\title{
Role of Insulin and Glucagon in the Response of Glucose and Alanine Kinetics in Burn-injured Patients
}

\author{
Farook Jahoor, David N. Herndon, and Robert R. Wolfe \\ Departments of Surgery, Anesthesiology, and Biochemistry, The University of Texas Medical Branch \\ and Shriners Burns Institute, Galveston, Texas 77550
}

\section{Abstract}

We investigated the roles of insulin and glucagon as mediators of changes in glucose and alanine kinetics during the hypermetabolic response to injury in 10 burn patients by infusing somatostatin with and without insulin replacement. Glucose and alanine kinetics were measured by primed-constant infusions of 6,6- $d_{2}$-glucose and $\left[3-{ }^{13}\right.$ Clalanine.

The basal rate of glucose production and alanine flux were significantly elevated in all patients. Lowering both hormones simultaneously caused an insignificant reduction in glucose production, but plasma glucose rose significantly $(P<0.01)$, because of reduced clearance. Alanine flux and total plasma amino nitrogen increased significantly $(P<0.05)$ above basal.

Selectively lowering glucagon concentration decreased glucose production $(P<0.05)$, and exogenous glucose was infused to maintain euglycemia. Alanine flux and total plasma amino nitrogen remained unchanged.

In severely burned patients (a) hyperglucagonemia stimulates increased glucose production, (b) basal insulin suppression glucose production, stimulates basal glucose clearance, and is important for regulation of plasma amino acid concentrations, and (c) the selective lowering of glucagon while maintaining basal insulin constant normalized glucose kinetics.

\section{Introduction}

The hypermetabolic response to thermal injury is characterized by hyperglycemia and a negative nitrogen balance due to alterations in protein and carbohydrate metabolism (1-3). The hyperglycemia results from an increased rate of glucose production (4), and in order to sustain this elevated rate of glucose production there is an increased rate of protein breakdown (primarily in skeletal muscle) to provide the extra amino acids needed for gluconeogenesis (5-7). Thus, the high rate of glucose production is directly related to the high rate of protein breakdown. Increased morbidity and mortality is associated with the acute protein malnutrition that can result from continual protein loss. Since the administration of exogenous glucose alone or glucose plus amino acids does not reverse the increased gluconeogenesis and nitrogen loss of severe injury and sepsis (7-9), a more detailed understanding of the mechanism underlying the changes in glucose and protein metabolism is needed, with the hope of ultimately manipulating it to clinical advantage.

Address correspondence to Dr. Wolfe.

Received for publication 13 November 1985 and in revised form 12 May 1986.

J. Clin. Invest.

(C) The American Society for Clinical Investigation, Inc.

0021-9738/86/09/0807/08 $\$ 1.00$

Volume 78, September 1986, 807-814
Alterations in the concentrations and activities of plasma glucagon and insulin levels in burn injury patients may be responsible for mediating the changes in glucose metabolism (912). There is general agreement that the elevated plasma glucagon is to some extent responsible for the increased rate of glucose production $(9,10,12)$, whereas the role of insulin as a regulator of hepatic glucose output and as a stimulator of glucose uptake by peripheral tissues may be diminished $(4,9,13)$. If this is true, then lowering glucagon to a lower level should normalize glucose metabolism in burn patients, even if insulin is simultaneously lowered. With this in mind, Wolfe and Burke (4) infused somatostatin to inhibit the pancreatic release of glucagon and insulin in burned patients for $30 \mathrm{~min}$. This procedure caused a significant reduction in the rate of glucose production. There was, however, a decreased clearance of glucose that was significantly correlated with the reduction in insulin concentration. When insulin was maintained at the basal level in one patient by reinfusion, the reduction in glucose production was not accompanied by a fall in glucose clearance, which suggests that basal insulin was effective in stimulating glucose clearance (14). The results of this study in one patient suggested that by selectively lowering glucagon concentration while maintaining basal insulin constant, it may be possible to reduce gluconeogenesis and maintain a normal glucose uptake (14).

Since definitive conclusions cannot be made from a onepatient study, we have used tracer techniques to further investigate the response of glucose and alanine kinetics to the manipulation of glucagon and insulin concentrations with somatostatin in 10 severely burned patients. We have compared the response to the simultaneous lowering of insulin and glucagon concentration with the response to selectively lowering only the glucagon concentration. It was our hypothesis that the latter procedure would suppress gluconeogenesis and thereby indirectly reduce the rate of net protein catabolism; and that the comparison of the response to somatostatin infusion with and without insulin replacement would establish the role of the basal insulin concentration in stimulating glucose uptake and suppressing glucose production. Alanine flux was measured because its release is markedly increased from peripheral tissues in severe injury (6) and because it is considered the key protein-derived gluconeogenic and ureagenic precursor (15). Its flux therefore represents an important link between the rate of hepatic gluconeogenesis and of nitrogen release from the periphery, and hence of protein catabolism.

\section{Methods}

Patients. 12 studies were performed in 10 burned patients, nine males and one female, who were admitted to the Burn Intensive Care Unit of The University of Texas Medical Branch in Galveston, TX. Characteristics of the individual patients are summarized in Table I. They ranged in age from 19 to $34 \mathrm{yr}$ and had a mean burn size of $60 \%$ of total body 


\begin{tabular}{|c|c|c|c|c|c|c|c|c|c|c|}
\hline \multirow[b]{2}{*}{ Patient } & \multirow[b]{2}{*}{ Weight } & \multirow[b]{2}{*}{$\begin{array}{l}\text { Percent BSA } \\
\text { burned } \\
\text { total } / 3^{\circ}\end{array}$} & \multirow[b]{2}{*}{ Associated injury } & \multirow[b]{2}{*}{$\begin{array}{l}\text { Type of } \\
\text { treatment }\end{array}$} & \multicolumn{2}{|c|}{$\begin{array}{l}\text { Postburn day } \\
\text { studied }\end{array}$} & \multicolumn{2}{|c|}{ Metabolic rate } & \multirow[b]{2}{*}{ Heart rate } & \multirow[b]{2}{*}{ Temperature } \\
\hline & & & & & Day & $\begin{array}{l}\text { Protocol } \\
\text { No. }\end{array}$ & $\begin{array}{l}\mathrm{kcals} / \mathrm{m}^{2} \\
\text { per h }\end{array}$ & $\begin{array}{l}\text { Percent above } \\
\text { predicted } \neq\end{array}$ & & \\
\hline & $k g$ & & & & & & & & beats per min & ${ }^{\circ} \mathrm{C}$ \\
\hline $\mathbf{A}$ & 55 & $75 / 52$ & None & $\mathbf{E}$ & 11 & I & 71 & 117 & 130 & 38.0 \\
\hline B & 76 & $90 / 0$ & None & $\mathbf{E}$ & 10 & I & 53 & 56 & 129 & 37.5 \\
\hline C & 62 & $64 / 18$ & None & C & 10 & I & 60 & 53 & 118 & 38.6 \\
\hline D & 76 & $44 / 0$ & None & C & 7 & I & 51 & 22 & 118 & 37.5 \\
\hline $\mathbf{E}$ & 90 & $65 / 40$ & Inhalation injury & $\mathbf{E}$ & 5 & I & - & - & 134 & 38.2 \\
\hline $\mathbf{F}$ & $85 ; 83$ & $54 / 20$ & None & $\mathrm{C}$ & $5 ; 8$ & I; II & - & - & $128 ; 126$ & $37.9 ; 37.9$ \\
\hline $\mathbf{G}$ & 86 & $60 / 40$ & None & $\mathbf{C}$ & 10 & II & 67 & 68 & 113 & 38.0 \\
\hline $\mathbf{H}$ & 65 & $48 / 45$ & Inhalation injury & $\mathbf{E}$ & 10 & II & 48 & 40 & 135 & 38.3 \\
\hline I & $79 ; 73$ & $47 / 17$ & Inhalation injury & $\mathbf{E}$ & $4 ; 12$ & II; II & $54 ; 48$ & $34 ; 25$ & $130 ; 106$ & $37.7 ; 37.5$ \\
\hline $\mathbf{J}$ & 92 & $50 / 17$ & $\begin{array}{l}\text { Open }(R) \text { hip reduction; } \\
\text { bladder laceration } \\
\text { repair with } \\
\text { implantation of } \\
\text { suprapubic catheter }\end{array}$ & $\mathrm{C}$ & 4 & II & 50 & 27 & 114 & 37.8 \\
\hline
\end{tabular}

* E, excised; C, conservative.

¥ Calculated from Harris-Benedict equation.

surface area (TBSA) ${ }^{1}$ (range, 44-90\% TBSA), of which 25\% was third degree (range, 0-50\% TBSA). Three patients were diagnosed as having smoke inhalation injury and a fourth patient received surgical treatment for a fractured right hip and a lacerated bladder with implantation of a suprapubic catheter on the first day after his injury, before his admission to the Burn Intensive Care Unit. The mean heart rate was $123 \pm 9$ beats per minute and the mean rectal temperature was $37.9 \pm 0.3 \mathrm{C}$. Their mean basal metabolic rate of $56 \pm 8.4 \mathrm{kcals} / \mathrm{m}^{2}$ per $\mathrm{h}$ (range, $48-71 \mathrm{kcals}$ ) $\mathrm{m}^{2}$ per $\mathrm{h}$ ) was $\sim 50 \%$ above the value predicted by the Harris-Benedict equation, which suggests that they were in a hypermetabolic state. Studies were performed between days 4 and 12 after injury. The exact day of study was determined by clinical factors, including stable hemodynamic and respiratory status, and also so that at least $2 \mathrm{~d}$ had passed since the last visit to the operating room, in order to allow vital signs to return to presurgical levels and hemodynamics to stabilize.

In accordance with another concurrently running study protocol, all patients of the study population were randomly assigned to one of two treatment groups. One group was treated by excising the burn wound within $72 \mathrm{~h}$ of injury, grafting with autograft meshed 1:4 (to the extent available donor site permitted) and/or overlaying with cadaveric allograft meshed 1:2. Subsequent reoperations were performed as donor sites became available, but all experiments were completed before any reoperations. The second group was treated conservatively with daily hydrotherapy and 12-hourly (two times daily) applications of Silvadene (Marion Laboratory, Inc., Kansas City, MO) and/or Sulfamylon (Winthrop-Breon Laboratories, New York, NY) on fine mesh gauge until granulating beds could receive 1:1.5 or 1:3 meshed autograft (21-63 d postburn).

In general, patients were cared for in private rooms with independently adjustable thermostats. The ambient temperature was selected in order to maintain the patient's rectal temperature at no less than $37.5^{\circ} \mathrm{C} . \mathrm{Pa}$ tients with rectal temperatures less than $37.5^{\circ} \mathrm{C}$ had their room's temperature increased until rectal temperature was above this minimum. Febrile patients (with rectal temperatures $>39^{\circ} \mathrm{C}$ ) were treated with 1,300 $\mathrm{mg}$ acetaminophen or $1,300 \mathrm{mg}$ aspirin. At the time of study all patients had rectal temperatures within the normal range (Table I), hence room temperature was not altered and no patient was given aspirin or acet-

1. Abbreviations used in this paper: TBSA, total body surface area. aminophen during the course of a study. Patients received nutrition either by mouth or gastric intubation and parenterally to reach their prescribed amount of nutrients. Caloric requirements were estimated as being 25 $\times$ body wt $(\mathrm{kg})+(40 \times$ percent $\mathrm{TBSB}) \mathrm{kcals}$, of which $\sim 60 \%$ was provided by carbohydrates.

The experimental protocol was approved by The University of Texas Medical Branch Institutional Review Board. Before their participation, the nature, purpose, and risks of the study were explained in detail to all patients and/or relatives in the presence of a patient advocate, and informed consent was obtained.

Materials. The isotopes infused as tracers in this study were 6, 6- $\mathrm{d}_{2}-$ glucose, 98\% enriched, obtained from Cambridge Isotope Laboratories (Woburn, MA) and $\left[3-{ }^{13} \mathrm{C}\right]$ alanine, $99.7 \%$ enriched, obtained from Merck Isotopes (Montreal, Canada). Sterile solutions of the isotopes were prepared in normal saline and passed through a $0.22-\mu \mathrm{m}$ filter (Millipore Corp., Bedford, MA) into sterile evacuated containers. For each infusion an aliquot of the infusate was analyzed for the exact isotope concentration in order to calculate the actual infusion rate for each patient.

Somatostatin was obtained from Bachem (Torrance, CA) and dissolved in sterile normal saline for infusion. Insulin for infusion was prepared from a stock solution $(1 \mathrm{mU} / \mathrm{ml}$ of $25 \%$ of human serum albumin solution) by dilution with normal saline.

Experimental design. Studies were performed in the postabsorptive state. Patients receiving total parenteral nutrition had all nutrition withheld for at least $6 \mathrm{~h}$ before the study. However, patients receiving oral/ gastric nutrition were fasted for a full $8 \mathrm{~h}$ before study. In all patients $0.45 \%$ saline was substituted for the enteral or parenteral alimentation to maintain a comparable fluid delivery rate and a normal state of hydration. At the time of study all patients had an arterial line and central venous line already in place for therapeutic purposes. All solutions were infused through the existing central venous line and blood samples were drawn from the arterial line.

The study consisted of two different experimental protocols (Fig. 1) and patients from the study population, regardless of their clinical treatment (conservative or early excision), were randomly assigned to either protocol. All the experiments performed in both protocols involved the primed-constant infusion of the isotopes $6,6-\mathrm{d}_{2}$-glucose and $\left[{ }^{13} \mathrm{C}\right]$ alanine.

Protocol 1. In this protocol six studies were performed in six patients (three excised, three conservative), from day 5 to day 11 postburn. The 
aim of this protocol was to measure the basal rates of glucose production and alanine flux and to assess the response to an acute and simultaneous suppression of insulin and glucagon release induced by the administration of somatostatin. The response of the basal plasma amino acid profile, cortisol, and human growth hormone levels was also assessed.

A primed-constant infusion of 6,6- $\mathrm{d}_{2}$-glucose (infusion rate of 0.034 $\mathrm{mg} / \mathrm{kg}^{-1} \cdot \mathrm{min}^{-1}$, prime of $2.72 \mathrm{mg} / \mathrm{kg}$ ) and $\left[3-{ }^{13} \mathrm{C}\right]$ alanine (infusion rate, $0.15 \mu \mathrm{mol} / \mathrm{kg}^{-1} \cdot \mathrm{min}^{-1}$; prime, $15 \mu \mathrm{mol} / \mathrm{kg}$ ) was started and maintained throughout a 4.5 -h study period (Fig. 1). After $1.5 \mathrm{~h}$ of only isotope infusion (the basal period), a constant infusion of somatostatin was started at the rate of $0.15 \mu \mathrm{g} / \mathrm{kg}^{-1} \cdot \mathrm{min}^{-1}$ and maintained for the remaining 3 $h$ of the study without interrupting the isotope infusion. A Harvard Model 2716 Syringe Infusion Pump (Harvard Apparatus Co., S. Natick, MA) was used for both infusions. During the somatostatin infusion the plasma glucose level of the patient was closely monitored by measuring the concentration on $0.25-\mathrm{ml}$ samples drawn every $10 \mathrm{~min}$ using a Glucose Analyzer 2 (Beckman Instruments, Inc., Fullerton, CA.).

A $10-\mathrm{ml}$ blood sample was drawn before the isotope infusion started and at 10 -min intervals during the last $30 \mathrm{~min}$ of the basal period. Samples were also drawn throughout the $3 \mathrm{~h}$ of somatostatin infusion at 20-min and then 30-min intervals (Fig. 1).

Protocol 2. Six infusions were performed in five patients, with one patient being studied twice. However, data from only one of the two studies in that patient were included in the results of this protocol $(n=5)$.

The aim of this protocol was to measure the basal rates of glucose production and alanine flux and to assess their response to a selective reduction of glucagon concentration by maintaining basal insulin level constant during the somatostatin administration period. The responses of the basal plasma amino acid profile, cortisol and human growth hormone were also assessed. Finally, the reproducibility during the hypermetabolic phase of all basal factors and their responses to the hormonal manipulation was assessed by studying the same patient on two occasions $8 \mathrm{~d}$ apart.

The isotope infusion and blood sampling procedures were as described for protocol 1. However, during the somatostatin infusion period, insulin was also infused at the rate of $0.2-0.3 \mathrm{mU} / \mathrm{kg}^{-1} \cdot \mathrm{min}^{-1}$. Plasma glucose concentration was monitored every $10 \mathrm{~min}$ and if it fell to $70 \mathrm{mg} / \mathrm{dl}$ an infusion of $20 \%$ glucose was started at rates ranging from 1.0 to $2.0 \mathrm{mg} /$ $\mathrm{kg}^{-1} \cdot \min ^{-1}$ in order to prevent hypoglycemia.

Analysis of samples. Blood samples were collected in ice-cold heparinized tubes and stored on ice until the end of the experiment, when plasma was separated by centrifugation at $4^{\circ} \mathrm{C}$. Aliquots of plasma were placed in tubes containing EDTA and trasylol and stored at $-20^{\circ} \mathrm{C}$ for hormone determinations. For the determination of amino acids, aliquots of plasma were immediately deproteinized with ice-cold $15 \%$ sulfosalicylic acid and stored at $-20^{\circ} \mathrm{C}$ for analysis the following day. The rest of the plasma was stored at $-20^{\circ} \mathrm{C}$ to be analyzed later for the isotopic enrichments of glucose and alanine.

\section{EXPERIMENTAL PROTOCOLS}
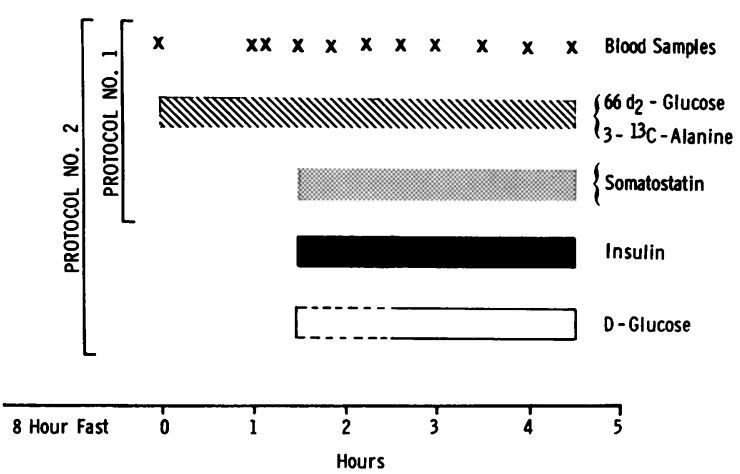

Figure 1. A schematic representation of the experimental protocols.
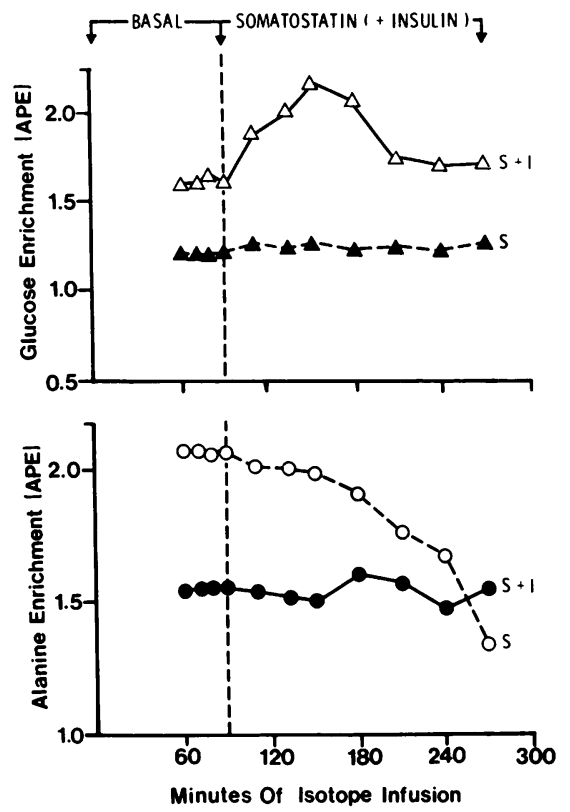

Figure 2. Plasma glucose and alanine enrichment-time curves of two patients studied in protocol $1(\mathrm{~S})$ and $2(\mathrm{~S}+\mathrm{I})$, respectively; showing plateaus in enrichments for both substrates in the basal period. The fall in glucose enrichment at 180 min during the $S+I$ infusion was due to the administration of exogenous glucose to maintain euglycemia.

Amino acid concentrations were determined by column chromatography on an autoanalyzer (121M; Beckman Instruments, Inc., Fullerton, CA). All hormones were determined by radioimmunoassay (RIA). Glucagon was determined as described by Faloona and Unger (16) using Unger's $30 \mathrm{~K}$ antibody. Insulin was determined with an insulin RIA kit (Amersham Corp., Arlington Heights, IL), cortisol was determined with a cortisol RIA kit (Micromedic Systems, Inc., Horsham, PA), and human growth hormone was determined with an HGH RIA kit (Cambridge Medical Diagnostics, Inc., Billerica, MA).

Isotopic enrichment of the plasma glucose was determined on a gas chromatography mass spectrometer (5985B, Hewlett-Packard Co., Palo Alto, CA) (17). To isolate glucose from plasma, plasma proteins were precipitated with $\mathrm{BA}(\mathrm{OH})_{2}$ and $\mathrm{ZnSO}_{4}$. The supernatant was sequentially passed through beds of anion resin (AG-1-X8) and cation resin (AG$50 \mathrm{~W}-\mathrm{X} 8$ ) in a chromatography column. The eluant was evaporated to dryness, the penta-acetate derivative was prepared, and the isotopic enrichment measured on the GCMS by selected ion monitoring at massto-change $(\mathrm{m} / \mathrm{e}) 200.1$ and 202.1.

The enrichment of alanine was determined on its $\mathrm{N}$-acetyl propyl ester derivative (17). Alanine was separated from the protein-free supernatant of $0.5 \mathrm{ml}$ plasma by desorption with $\mathrm{NH}_{4} \mathrm{OH}$ from Dowex 50W-X8 200/400 mesh $\mathrm{H}^{+}$cationic resin, and the NAP derivative was prepared from the dried eluant. The chemical ionization spectrum was used and the ions at $\mathrm{m} / \mathrm{e} \mathbf{1 7 4 . 2}$ and 175.2 were selected for monitoring.

Calculations. The rate of endogenous glucose production and alanine flux was calculated according to the Steele equation (18). Rate of appearance $\left(R_{\mathbf{a}}\right)=(($ MPE Infusion/MPE Plasma $)-1) \times F$, where MPE $=$ mole percent excess and $\mathrm{F}=$ rate of infusion of the isotope $(\mu \mathrm{mol}$ [or $\mathrm{mg}] / \mathrm{kg}^{-1} \cdot \mathrm{min}^{-1}$ ). This equation is only valid in a physiological and isotopic steady state, that is, when neither the plasma concentration nor isotopic enrichment of the substrate is changing with time. These criteria were satisfied for both glucose and alanine during the basal period of the experiment (Fig. 2). Under such conditions the $R_{\mathrm{a}}$ of glucose is equal to its endogenous production, which in turn is equal to its rate of uptake. The rate of clearance of both substrates was calculated by dividing their rate of uptake (disappearance) by their corresponding plasma concentration. 

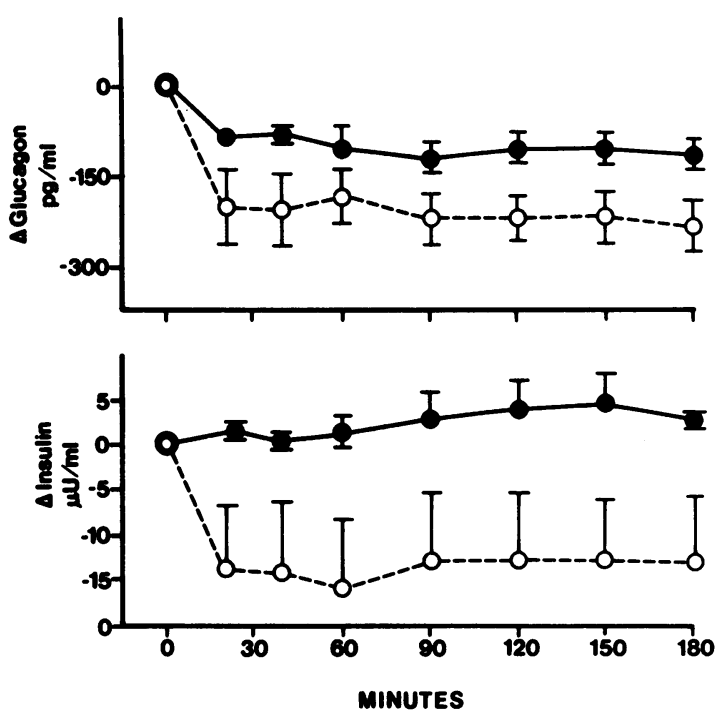

Figure 3. Change from basal of plasma insulin and glucagon concentration during a somatostatin (- - O- ) and a somatostatin plus insulin infusion (-•-).

During the somatostatin ( \pm insulin) infusion periods both the physiological and isotopic steady states were disrupted. In this situation the non-steady state form of the Steele equation was used to calculate alanine and glucose rates of appearance and uptake (18). In experiments in which exogenous glucose was infused to maintain normoglycemia, the actual endogenous glucose production rate was obtained by subtracting the rate of unlabeled glucose infusion from the total rate of appearance of glucose as measured with the isotopic tracer.

Statistical analysis. Because of the crossover design of both experimental protocols, Dunnett's (the paired) $t$ test was used to compare all basal values with the values obtained during the somatostatin infusion period. To compare data from two independent groups, for example, conservative vs. excised patients or burned patient vs. normal controls, the non-paired $t$ test was employed. All results are presented as mean \pm SEM.

\section{Results}

Protocol 1. The basal insulin $(24 \pm 8 \mu \mathrm{U} / \mathrm{ml})$ and glucagon $(486 \pm 96 \mathrm{pg} / \mathrm{ml})$ concentrations of this group of patients were significantly elevated $(P<0.01)$ when compared with the values obtained for normal volunteers. All values for normal postabsorptive subjects were obtained from a control study which employed the same protocols as the present study and was performed concurrently (19). The somatostatin infusion significantly reduced $(P<0.001)$ the plasma concentrations of both hormones. There was a mean reduction of $59 \%$ in plasma insulin and a $45 \%$ reduction in plasma glucagon (Fig. 3 and Table II). These reductions were less than has been observed in normal volunteers given somatostatin in our control studies and by others $(19,20,21)$. As a result, during somatostatin infusion in burn patients, the insulin level was still within the range of normal volunteers, and glucagon remained about two times higher than normal control values (19). Basal cortisol concentration (35 \pm 7 $\mu \mathrm{g} / \mathrm{dl}$ ) was markedly elevated when compared with the value reported for normal volunteers (4), and was unaffected by the somatostatin infusion. Human growth hormone $(2.7 \pm 0.5 \mathrm{ng} /$ ml) was within the normal range, and although somatostatin induced a reduction in its concentration, the change was not significant (Table II).

The rate of basal glucose production was $3.75 \pm 0.5 \mathrm{mg} /$ $\mathrm{kg}^{-1} \cdot \mathrm{min}^{-1}$, which is significantly greater than the value of $2.38 \pm 0.07 \mathrm{mg} / \mathrm{kg}^{-1} \cdot \mathrm{min}^{-1}$ obtained for normal postabsorptive volunteers (19). Although somatostatin administration induced a decrease in the rate of glucose production, the magnitude of this change was not statistically significant (Fig. 4). Similarly, the rate of glucose uptake during the somatostatin infusion, $3.02 \pm 0.23 \mathrm{mg} / \mathrm{kg}^{-1} \cdot \mathrm{min}^{-1}$, was not significantly different from the basal value of $3.35 \pm 0.53 \mathrm{mg} / \mathrm{kg}^{-1} \cdot \mathrm{min}^{-1}$. Basal plasma glucose concentration $(115 \pm 15 \mathrm{mg} / \mathrm{dl})$ was significantly higher $(P$ $<0.05)$ than the value $(91 \pm 2.0 \mathrm{mg} / \mathrm{dl})$ obtained for normal volunteers (19). There was an initial fall in glucose concentration over the first 20 min of somatostatin infusion, after which it gradually increased. After $90 \mathrm{~min}$, glucose concentration reached a level that was significantly higher than basal $(P<0.01)$, indicating a reduced clearance of glucose from plasma $(P<0.05)$. (Fig. 4).

Somatostatin infusion alone caused a significant increase $(P$ $<0.05$ ) in alanine flux $90 \mathrm{~min}$ after the infusion started (Fig. 5). There was no significant change in alanine clearance rate.

The plasma levels of all nonessential amino acids and three essential amino acids (threonine, methionine, arginine) were

Table II. Hormonal Response to Somatostatin Infusion

\begin{tabular}{|c|c|c|c|c|c|c|c|c|c|}
\hline \multirow[b]{2}{*}{ Hormone } & \multirow[b]{2}{*}{ Basal } & \multicolumn{8}{|c|}{ Minutes of somatostatin infusion } \\
\hline & & 20 & 40 & 60 & 90 & 120 & 150 & 180 & $P^{*}$ \\
\hline Insulin $(\mu U / m l)$ & $24 \pm 8 \neq$ & $10 \pm 1.5$ & $10 \pm 1.4$ & $8 \pm 1.3$ & $11 \pm 1.9$ & $11 \pm 1.1$ & $11 \pm 2.3$ & $11 \pm 1.7$ & $<0.001$ \\
\hline Glucagon $(p g / m l)$ & $486 \pm 96$ & $283 \pm 72$ & $276 \pm 66$ & $296 \pm 72$ & $257 \pm 66$ & $261 \pm 67$ & $266 \pm 76$ & $246 \pm 69$ & $<0.001$ \\
\hline Cortisol $(\mu g / d l)$ & $35 \pm 7$ & $33 \pm 7$ & $35 \pm 7$ & $35 \pm 7$ & $36 \pm 7$ & $37 \pm 6$ & $37 \pm 5$ & $37 \pm 4$ & NS \\
\hline \multirow[t]{2}{*}{ Growth hormone $(\mathrm{ng} / \mathrm{ml})$} & $2.7 \pm 0.5$ & $2.1 \pm 0.4$ & $2.0 \pm 0.3$ & $1.7 \pm 0.3$ & $1.7 \pm 0.3$ & $1.9 \pm 0.3$ & $1.9 \pm 0.3$ & $1.9 \pm 0.3$ & NS \\
\hline & & \multicolumn{8}{|c|}{ Somatostatin + insulin infusion } \\
\hline Insulin $(\mu U / m l)$ & $12 \pm 1.2 \S$ & $12 \pm 1.7$ & $11 \pm 1.3$ & $12 \pm 1.5$ & $13 \pm 2.5$ & $14 \pm 2.9$ & $14 \pm 2.5$ & $14 \pm 1.1$ & NS \\
\hline Glucagon $(p g / m l)$ & $365 \pm 129$ & $287 \pm 123$ & $280 \pm 129$ & $262 \pm 118$ & $236 \pm 114$ & $251 \pm 110$ & $258 \pm 119$ & $255 \pm 117$ & $<0.001$ \\
\hline Cortisol $(\mu g / d l)$ & $34 \pm 8$ & $35 \pm 8$ & $33 \pm 8$ & $33 \pm 6$ & $27 \pm 5$ & $32 \pm 8$ & $33 \pm 7$ & $31 \pm 6$ & NS \\
\hline Growth hormone $(n g / m l)$ & $1.8 \pm 0.3$ & $1.5 \pm 0.3$ & $1.5 \pm 0.3$ & $1.2 \pm 0.2$ & $1.2 \pm 0.2$ & $1.1 \pm 0.2$ & $1.2 \pm 0.2$ & $1.3 \pm 0.2$ & NS \\
\hline
\end{tabular}

Values are mean $\pm S E M . \quad *$ Significance of difference between basal and postsomatostatin $(+$ insulin) values $($ paired $t$ test). $\quad ¥ n=6$. $\S n=5$. 

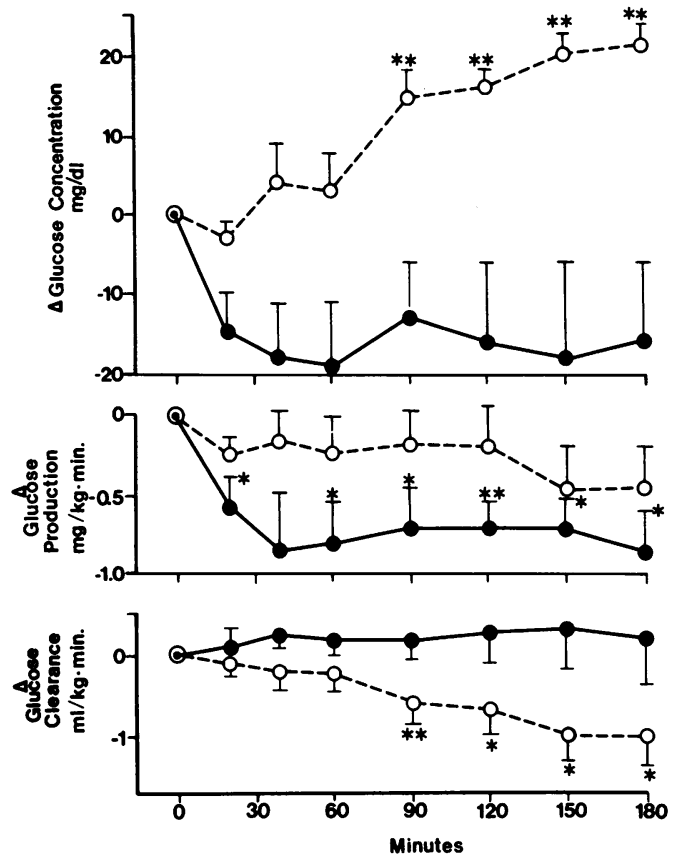

Figure 4. Change from basal in plasma glucose concentration, glucose production rate, and glucose clearance due to a somatostatin $(--0--)$ or somatostatin plus insulin $(-\bullet-)$ infusion. Results are expressed as mean \pm SEM. ${ }^{*} P<0.05,{ }^{* *} P<0.01$. Values were significantly different from basal $(P<0.05)$.

significantly lower $(P<0.01)$ in burned patients when compared with values obtained from six normal postabsorptive subjects (unpublished data) and the normal values reported by others $(22,23)$. Valine was not different, but all the other essential amino acids were significantly elevated $(P<0.05)$ above normal control values. After $3 \mathrm{~h}$ of somatostatin infusion, the plasma levels of all amino acids increased significantly $(P<0.05)$ above basal values, causing total amino nitrogen to increase significantly

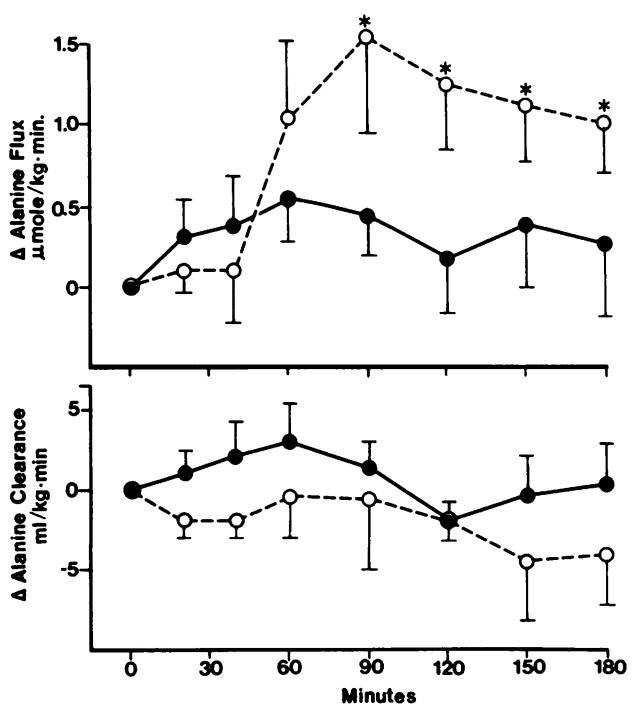

Figure 5. Effect of somatostatin (- - ---$)$ and somatostatin plus insulin (- -$)$ infusion on alanine flux rates and clearance in burn patients. Values are expressed as the difference from the basal value. *Values were significantly different from basal $(P<0.05)$.
$(P<0.05)$ from the basal value of $1,742 \pm 154 \mu \mathrm{M}$ to $2,248 \pm 165$ $\mu \mathrm{M}$ (Table III).

Protocol 2. The basal plasma insulin $(12 \pm 1.2 \mu \mathrm{U} / \mathrm{ml})$ and glucagon $(365 \pm 129 \mathrm{pg} / \mathrm{ml})$ concentrations of this group were not as markedly elevated as the values obtained for the group studied in protocol 1 , and insulin levels were within the range for normal volunteers (19) (Table II). The infusion of somatostatin plus insulin elicited a $30 \%$ decrease in glucagon concentration while maintaining basal insulin levels, thereby creating a selective drop in glucagon (Fig. 3). Cortisol and human growth hormone were again not influenced significantly by somatostatin (+ insulin) infusion (Table II).

The basal glucose production rate $\left(3.71 \pm 0.4 \mathrm{mg} / \mathrm{kg}^{-1} \cdot \mathrm{min}^{-1}\right)$ was almost identical to the rate obtained for the first group of patients, and decreased significantly $(P<0.05)$ in response to the selective lowering of glucagon (Fig. 4). The basal value of glucose uptake, $3.5 \pm 0.43 \mathrm{mg} / \mathrm{kg}^{-1} \cdot \mathrm{min}^{-1}$, did not change during the selective lowering of glucagon $\left(3.21 \pm 0.45 \mathrm{mg} / \mathrm{kg}^{-1} \cdot \mathrm{min}^{-1}\right)$. As a consequence, basal glucose concentration $(102 \pm 12 \mathrm{mg} / \mathrm{dl})$ fell rapidly during the first $20 \mathrm{~min}$ of somatostatin plus insulin infusion and exogenous glucose had to be infused in order to maintain the plasma concentration above $70 \mathrm{mg} / \mathrm{dl}$. The rate of glucose clearance remained unchanged throughout the infusion (Fig. 4).

Alanine flux remained unchanged during the somatostatin plus insulin infusion. Alanine clearance was also unaffected (Fig. 5). The basal amino acid profile of this group was similar to that of the first group (Tables III and IV). In contrast to the situation when insulin was not replaced, there were no significant changes in the plasma concentrations of any amino acids in response to the somatostatin plus insulin infusion, except for lysine and histidine, whose concentrations increased significantly $(P<0.05)$.

Table III. Plasma Amino Acid Levels in

Postabsorptive Burn Patients $(n=6)$ in the Basal State and after $3 h$ of Somatostatin Infusion

\begin{tabular}{lccc}
\hline Amino acid & Basal & Somatostatin & $P^{*}$ \\
\hline & $\mu M$ & $\mu M$ & \\
Aspartic acid & $11 \pm 0.6$ & $14 \pm 0.7$ & $<0.05$ \\
Glutamic acid & $64 \pm 5$ & $86 \pm 14$ & $<0.05$ \\
Glutamine & $277 \pm 59$ & $394 \pm 61$ & $<0.05$ \\
Alanine & $213 \pm 25$ & $253 \pm 28$ & $<0.05$ \\
Glycine & $136 \pm 8$ & $154 \pm 11$ & $<0.05$ \\
Serine & $68 \pm 8$ & $80 \pm 5$ & $<0.01$ \\
Proline & $119 \pm 6$ & $141 \pm 9$ & $<0.01$ \\
Threonine & $78 \pm 6$ & $101 \pm 6$ & $<0.01$ \\
Methionine & $23 \pm 3$ & $37 \pm 5$ & $<0.01$ \\
Lysine & $156 \pm 15$ & $198 \pm 17$ & $<0.05$ \\
Histidine & $50 \pm 6$ & $62 \pm 7$ & $<0.05$ \\
Valine & $180 \pm 18$ & $221 \pm 17$ & $<0.05$ \\
Isoleucine & $56 \pm 6$ & $79 \pm 6$ & $<0.01$ \\
Leucine & $112 \pm 12$ & $161 \pm 11$ & $<0.01$ \\
Tyrosine & $61 \pm 5$ & $73 \pm 8$ & $<0.05$ \\
Phenylalanine & $83 \pm 4$ & $100 \pm 3$ & $<0.05$ \\
Arginine & $55 \pm 7$ & $94 \pm 11$ & $<0.01$ \\
Total amino-N & $1,742 \pm 154$ & $2,248 \pm 165$ & $<0.05$ \\
& & &
\end{tabular}

Values are mean \pm SEM.

* Significance of difference between basal and postsomatostatin values (paired $t$ test). 
There was no significant change in total plasma amino nitrogen (Table IV).

In order to assess the reproducibility of the response, the same patient was studied according to protocol 2 on postburn days 4 and 12. As shown in Fig. 6, the responses elicited by the infusion were similar in both studies.

In order to determine if the mode of clinical treatment (excised or nonexcised) had any influence on the observed responses, the study population for each protocol was divided into an excised and a nonexcised group. Comparison of the pooled basal data (Table V) suggested no marked differences, except for a higher basal plasma glucose concentration in the nonexcised group (132 \pm 14 vs. $92 \pm 5 \mathrm{mg} / \mathrm{dl}, P=0.03$ ). The nature and magnitude of response to somatostatin ( \pm insulin) did not differ according to mode of treatment.

\section{Discussion}

The primary aim of this study was to assess the roles of glucagon and insulin in mediating the changes in glucose kinetics in severe burn injury. We found that the elevated glucagon concentration was important in stimulating glucose production, and that basal insulin was effective in stimulating basal glucose clearance. In addition, our results suggested that basal insulin was also involved in suppressing glucose production and the release of amino acids from peripheral tissues, implying that it inhibited protein catabolism.

The results of this study support the role of glucagon as the principal mediator of the increase in basal glucose production, since the lowering of glucagon concentration in both protocols caused a decrease in glucose production. Since an infusion of glucagon into normal man and dog induces only a transient increase in glucose production (24-26), it can be argued that the stimulatory effect of the hormone is transitory and lacks the ability to cause a sustained increase in glucose production.

Table IV. Plasma Amino Acid Levels in Postabsorptive Burn Patients $(n=5)$ in the Basal State and after a 3-h Somatostatin + Insulin Infusion

\begin{tabular}{lccl}
\hline Amino acid & Basal & Somatostatin + insulin & $P^{*}$ \\
\hline & $\mu M$ & $\mu M$ & \\
Aspartic acid & $12 \pm 1$ & $13 \pm 2$ & NS \\
Glutamic acid & $64 \pm 11$ & $49 \pm 12$ & NS \\
Glutamine & $218 \pm 30$ & $259 \pm 20$ & NS \\
Alanine & $203 \pm 27$ & $211 \pm 22$ & NS \\
Glycine & $108 \pm 12$ & $115 \pm 14$ & NS \\
Serine & $54 \pm 7$ & $52 \pm 7$ & NS \\
Proline & $129 \pm 12$ & $139 \pm 14$ & NS \\
Threonine & $59 \pm 6$ & $67 \pm 7$ & NS \\
Methionine & $24 \pm 4$ & $29 \pm 7$ & NS \\
Lysine & $107 \pm 14$ & $126 \pm 14$ & $P<0.05$ \\
Histidine & $46 \pm 5$ & $56 \pm 6$ & $P<0.05$ \\
Valine & $167 \pm 22$ & $164 \pm 20$ & NS \\
Isoleucine & $48 \pm 8$ & $53 \pm 10$ & NS \\
Leucine & $102 \pm 11$ & $108 \pm 13$ & NS \\
Tyrosine & $54 \pm 6$ & $56 \pm 13$ & NS \\
Phenylalanine & $92 \pm 7$ & $94 \pm 5$ & NS \\
Arginine & $49 \pm 7$ & $64 \pm 5$ & NS \\
Total amino-N & $1,550 \pm 152$ & $1,655 \pm 147$ & NS \\
\hline
\end{tabular}

Values are mean \pm SEM.

* Significance of difference between basal and postsomatostatin + insulin values (paired $t$ test).
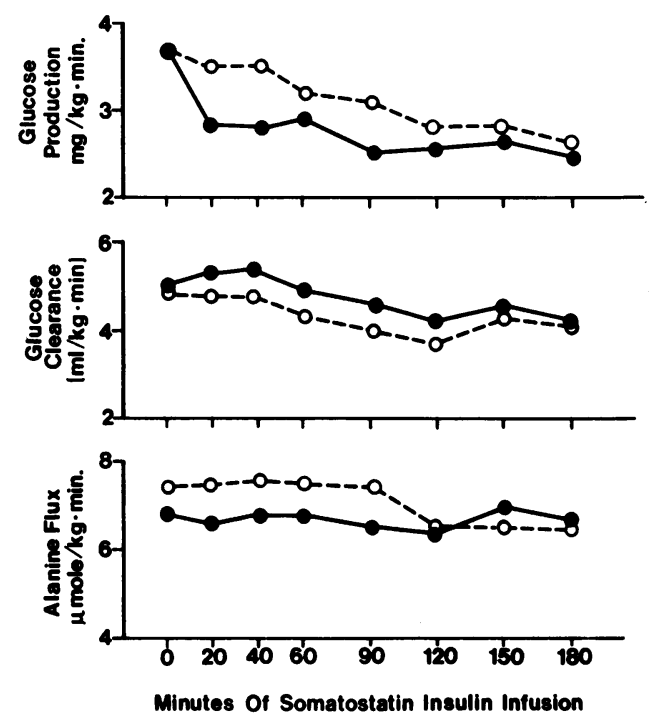

Figure 6. Results from patient who was infused with somatostatin plus insulin (protocol 2$)$ on day $4(-\bullet-)$ and day $12(--0--)$ postburn. The changes in glucose and alanine kinetics were similar in both studies.

However, when glucagon is infused in combination with cortisol, the increase in glucose production is sustained $(24,25)$. Thus, the simultaneously elevated cortisol level in these burn patients may be responsible for amplifying and sustaining the effect of hyperglucagonemia on glucose production. Although the incomplete suppression of glucagon by somatostatin in the patients makes it impossible to quantify the exact contribution of glucagon in stimulating glucose production, the fact that even a partial suppression of glucagon elicited a reduction in glucose production strengthens the conclusion that hyperglucagonemia is responsible for stimulating the elevated rate of glucose production even more than if the glucagon secretion had been totally suppressed.

The crossover experimental design employed in both protocols enabled us to draw conclusions regarding the role of glucagon, irrespective of the somewhat variable condition of each patient. Thus, our conclusions were not based on comparisons of the values in burn patients with basal values from normal controls, but rather on the direction of change from basal in each patient as a consequence of the hormonal manipulations. Furthermore, intersubject variability was minimized to the extent possible in a group of patients so severely injured. We selected only patients with burns covering $>40 \%$ of the body surface, since it has been found that the overall metabolic rate (27), as well as glucose kinetics (4), become unrelated to burn size with injuries $>40 \%$. Also, studies have failed to demonstrate marked effects of the days postburn on the response when the range of days was as small as it was in our study (e.g., 4). This was confirmed in the one subject in whom we were able to perform two identical studies, one at day four and one at day 12. There was no difference between the basal kinetic parameters measured, and the response to somatostatin plus insulin administration was similar in both experiments.

Not only do the results of our study show the role of glucagon in stimulating basal glucose production, but they indicate a role of basal insulin as an inhibitor of glucose production. Although the lowering of glucagon concentration in both protocols was associated with a decrease in glucose production, the magnitude 
Table V. Basal Hormonal Levels, Glucose, and Alanine Kinetics of Excised vs. Nonexcised

\begin{tabular}{|c|c|c|c|c|c|c|c|c|c|}
\hline Excised patient & Insulin & Glucagon & Cortisol & $\begin{array}{l}\text { Growth } \\
\text { hormone }\end{array}$ & Glucose & $\begin{array}{l}\text { Glucose } \\
\text { production }\end{array}$ & $\begin{array}{l}\text { Glucose } \\
\text { clearance }\end{array}$ & Alanine flux & $\begin{array}{l}\text { Alanine } \\
\text { clearance }\end{array}$ \\
\hline & $\mu U / m l$ & $p g / m l$ & $\mu g / d l$ & $n g / m l$ & $m g / d l$ & $\mathrm{mg} / \mathrm{kg} \cdot \min$ & $\mathrm{ml} / \mathrm{kg} \cdot \min$ & $\mu \mathrm{mol} / \mathrm{kg} \cdot \mathrm{min}$ & $\mathrm{ml} / \mathrm{kg} \cdot \min$ \\
\hline A & 12 & 555 & 22 & 4.25 & 94 & 5.01 & 5.3 & 16.3 & 96 \\
\hline B & 21 & 490 & 34 & 2.60 & 87 & 3.12 & 3.6 & 11.4 & 62 \\
\hline $\mathrm{E}$ & 16 & 746 & 41 & 1.00 & 102 & 3.12 & 3.0 & 5.8 & 24 \\
\hline $\mathbf{H}$ & 15 & 279 & 27 & 2.20 & 104 & 2.74 & 2.6 & 9.4 & 43 \\
\hline I & 10 & 755 & 45 & 2.33 & 75 & 3.70 & 4.9 & 6.9 & 36 \\
\hline Mean & 15 & 565 & 34 & 2.48 & 92 & 3.54 & 3.9 & 10 & 52 \\
\hline SEM & 1.9 & 88 & 4 & 0.52 & 5 & 0.40 & 0.5 & 1.9 & 12 \\
\hline \multicolumn{10}{|l|}{ Nonexcised } \\
\hline $\mathrm{C}$ & 10 & 335 & 19 & 3.95 & 85 & 5.72 & 6.7 & - & - \\
\hline D & 22 & 680 & 65 & 2.85 & 170 & 2.66 & 1.6 & 3.8 & 18 \\
\hline$F$ & 62 & 107 & 19 & 1.43 & 152 & 2.74 & 1.8 & 6.7 & 23 \\
\hline G & 9 & 297 & 11 & 2.30 & 119 & 3.39 & 2.8 & 9.7 & 53 \\
\hline $\mathbf{J}$ & 9 & 282 & 40 & 0.32 & 136 & 5.02 & 3.7 & 5.3 & 36 \\
\hline Mean & 22 & 340 & 31 & 2.17 & 132 & 3.91 & 3.3 & 6.4 & 33 \\
\hline SEM & 10 & 93 & 10 & 0.61 & 14 & 0.62 & 0.9 & 1.2 & 8 \\
\hline$P^{*}$ & NS & NS & NS & NS & 0.03 & NS & NS & NS & NS \\
\hline
\end{tabular}

$n=5$ for each group. * Unpaired $t$ test.

of the reduction when basal insulin was maintained constant was twice that when basal insulin was allowed to fall. These results are consistent with the finding of Cherrington et al. (28) that an insulin deficiency in normal dogs resulted in a $52 \%$ increase in the rate of glucose production, which was abolished when insulin levels were restored to normal. Also, Ward et al. (29) reported that selective insulin deficiency in normal man caused a significant increase in glucose production. It has been shown that low-dose insulin infusions lowered the blood glucose concentration of insulin-withdrawn diabetics entirely by reducing glucose production (30). On the other hand, previous studies have indicated a hepatic insulin resistance in burn injury, in that increases in insulin concentration induced by glucose infusion were not as effective in suppressing glucose production in burned patients as in normal volunteers (4). Apparently, resistance to the action of increased levels of insulin in burn injury does not imply a lack of normal effectiveness of the basal concentration of the hormone.

The role of basal insulin as a stimulator of glucose utilization in these burn patients was established by the significant reduction in glucose clearance during the simultaneous lowering of insulin and glucagon, and the maintenance of glucose clearance at the basal level when insulin concentration was maintained. Since the rates of glucose uptake in the two protocols were comparable (owing to the infusion of glucose in protocol 2), the only interpretation of differences in glucose clearance is that the ability of tissues to take up glucose was greater in the group with the basal insulin level. This finding is in agreement with the results of similar experiments conducted in normal volunteers which have shown that the lowering of basal insulin concentration is always accompanied by a significant reduction in glucose uptake, regardless of whether or not glucagon is allowed to fall $(20,26)$. It is, however, at odds with the general belief that the reduced glucose tolerance and hyperglycemia of injury (particularly during a glucose infusion) is a direct consequence of an inability of insulin to stimulate glucose uptake ("insulin resistance"). Indeed, when burned patients are presented with an exogenous glucose load, although there is an exaggerated insulin response, it is not associated with a corresponding increase in glucose disposal comparable to that of normal volunteers $(4,13,31)$. The decrease in sensitivity to the hypoglycemic action of insulin during glucose infusion in those studies led to the conclusion that the elevated rate of basal glucose uptake must be taking place in insulinindependent tissues $(4,13)$. The current study proves that this is not the case, however, since basal glucose clearance falls when the basal insulin level is reduced. It seems that the diminished responsiveness to insulin in burn injury only becomes evident at high concentrations of insulin.

The elevated alanine flux of these burn patients is consistent with the findings of arterio-venous difference studies in which injured patients had an increased peripheral release of amino acids, with alanine accounting for the major increase $(6,32)$, and in which injured septic patients had an increase in hepatic alanine uptake (7). This increased amino acid flux is believed to be a consequence of an accelerated net protein catabolism in peripheral tissues $(6,7,32)$. Results of the current study indicate that basal insulin (rather than glucagon) acts to conserve protein by restraining this increased amino acid release, as there was no significant change in alanine flux or in total plasma amino nitrogen when basal insulin concentration was maintained constant. This is consistent with the finding in normal volunteers that declines in plasma amino acid levels after systemic insulinization are due to inhibition of muscle release (22). Since the plasma concentration of amino acids reflect a balance between peripheral tissue release and visceral organ uptake (33) and the uptake of alanine and the essential amino acids leucine, lysine, and valine are not impaired in burn patients (34), the significantly increased concentration of all plasma amino acids when insulin was reduced, further supports an increased peripheral release due to accelerated net protein catabolism.

Another fact brought to light by the alanine flux data is that glucose production in burn patients is controlled at the liver and not by precursor supply. During the simultaneous lowering of insulin and glucagon concentrations, glucose production decreased despite an increase in the delivery of alanine to the liver. Thus, although peripheral net protein breakdown and hepatic gluconeogenesis are related, gluconeogenesis is not "driven" by the accelerated rate of net protein breakdown. Furthermore, as 
indicated by both amino acid concentrations and alanine flux, normalization of alanine production does not necessarily normalize peripheral protein metabolism.

The clinical implication of these findings is that somatostatin may be a useful adjunct to nutritional support in severely burned patients. However, studies of longer duration than $3 \mathrm{~h}$ are first necessary to establish that the response we have observed will be sustained, and the effect of hormone manipulation on protein metabolism should be more directly assessed.

\section{Acknowledgments}

The authors wish to thank Dr. Sally Abston and her staff for making it possible to perform these studies in the Burn Intensive Care Unit at The University of Texas Medical Branch, and the nursing staff for their dedicated assistance in the performance of the experiments. We are grateful to Thomas Rutan for his expert measurement of metabolic rate in the patients. We are also indebted to Marta Wolfe and her staff, Amy Amatong, Sarada Kunapuli and Susan Fons for analyses of samples and mass spectrometric measurements and to Judy Chadwick for the typing and preparation of this manuscript.

This study was supported by Army Contract No. DAMD 17-84C4004, National Institutes of Health grant AM-33952, and a grant from the Shriners Hospital.

\section{References}

1. Wolfe, R. R., M. J. Durkot, and M. H. Wolfe. 1982. Effect of thermal injury on energy metabolism, substrate kinetics and hormonal concentrations. Circ. Shock. 9:383-394.

2. Hinton, P., S. Littlejohn, S. P. Allison, and J. Lloyd. 1971. Insulin and glucose to reduce catabolic response to injury in burned patients. Lancet. i:767-769.

3. Allison, S. P., P. Hinton, and M. J. Chamberlain. 1968. Intravenous glucose-tolerance, insulin and free fatty-acid levels in burned patients. Lancet. ii:113-116.

4. Wolfe, R. R., M. J. Durkot, J. R. Allsop, and J. F. Burke. 1979. Glucose metabolism in severely burned patients. Metab. Clin. Exp. 28: 1031-1039.

5. Wolfe, R. R., R. D. Goodenough, J. F. Burke and M. H. Wolfe. 1983. Response of protein and urea kinetics in burned patients to different levels of protein intake. Ann. Surg. 197:163-171.

6. Aulick, L. H., and D. W. Wilmore. 1979. Increased peripheral amino acid release following burn injury. Surgery. 85:560-565.

7. Gump, F. E., C. L. Long, J. W. Geiger, and J. M. Kinney. 1975. The significance of altered gluconeogenesis in surgical catabolism. $J$. Trauma. 15:704-713.

8. Woolfson, A. M. J., R. V. Heatley, and S. P. Allison. 1979. Insulin to inhibit protein catabolism after injury. N. Engl. J. Med. 300:14-17.

9. Wilmore, D. W., A. D. Mason, Jr., and B. A. Pruitt, Jr. 1976. Insulin response to glucose in hypermetabolic burn patients. Ann. Surg. 183:314-320.

10. Wilmore, D. W., J. A. Moylan, B. A. Pruitt, Jr., C. A. Lindsey, G. R. Faloona, and R. H. Unger. 1974. Hyperglucagonemia after burns. Lancet. i:73-75.

11. Unger, R. H. 1972. Glucagon and the insulin: glucagon ratio in diabetes and other catabolic illness. Diabetes. 20:834-838.

12. Meguid, M. M., M. F. Brennan, T. T. Aoki, W. A. Muller, M. R. Ball, and F. D. Moore. 1973. The role of insulin and glucagon in acute trauma. Surg. Forum. 24:97-98.

13. Black, P. R., D. C. Brooks, P. Q. Bessey, R. R. Wolfe, and D. W. Wilmore. 1982. Mechanisms of insulin resistance following injury. Ann. Surg. 196:420-435.

14. Wolfe, R. R., and J. F. Burke. 1982. Somatostatin infusion inhibits glucose production in burn patients. Circ. Shock. 9:521-527.
15. Ruderman, N. B. 1975. Muscle amino acid metabolism and gluconeogenesis. Ann. Rev. Med. 26:245-258.

16. Faloona, G. R., and R. H. Unger. 1974. Glucagon. In Methods of Hormone Radioimmunoassay. M. B. Jaffe and H. R. Behrman, editors. Academic Press, Inc., New York. 317.

17. Wolfe, R. R. 1984. Gas chromatography-mass spectrometry methods. In Tracers in Metabolic Research: Radioisotopes and Stable Isotope/Mass Spectrometry Methods. Alan R. Liss, Inc., New York. 261274.

18. Steele, R. 1959. Influences of glucose loading and of injected insulin on hepatic glucose output. Ann. NY Acad. Sci. 82:420-430.

19. Wolfe, R. R., J. H. F. Shaw, F. Jahoor, D. N. Herndon, and M. H. Wolfe. 1986. Response to glucose infusion in humans: role of changes in insulin concentration. Am. J. Physiol. 250(Endocrinol. Metab. 13):E306-E311.

20. Felber, J. P., D. Thiebaud, E. Maeder, E. Jequier, R. Hendler, and R. A. DeFronzo. 1983. Effect of somatostatin-induced insulinopenia on glucose oxidation in man. Diabetologia. 25:325-330.

21. Rabin, D., G. L. Mueller, W. W. Lacy, and J. E. Liljenquist. 1979. Splanchnic metabolism of alanine in intact man. Effects of somatostatin and somatostatin plus insulin. Diabetes. 28:486-490.

22. Pozefsky, T., P. Felig, J. B. Tobin, J. S. Soeldner, and G. F. Cahill, Jr. 1969. Amino acid balance across tissues of the forearm in postabsorptive man. Effects of insulin at two dose levels. J. Clin. Invest. 48:2273-2282.

23. Felig, P., and J. Wahren. 1971. Influence of endogenous insulin secretion on splanchnic glucose and amino acid metabolism in man. $J$. Clin. Invest. 50:1702-1711.

24. Eigler, N., L. Sacca, and R. S. Sherwin. 1979. Synergistic interactions of physiologic increments of glucagon, epinephrine and cortisol in the dog. J. Clin. Invest. 63:114-123.

25. Bessey, P. Q., J. M. Watters, T. T. Aoki, and D. W. Wilmore. Combined hormonal infusion stimulates the metabolic response to injury. Ann. Surg. 200:264-281.

26. Sherwin, R. S., W. Tamborlane, R. Hendler, L. Sacca, R. A. DeFronzo, and P. Felig. 1977. Influence of glucagon replacement on the hyperglycemic and hyperketonemic response to prolonged somatostatin infusion in normal man. J. Clin. Endocrinol. Metab. 45:1104-1107.

27. Wilmore, D. W., J. M. Long, A. D. Mason, R. W. Skreen, and B. A. Pruitt, Jr. 1974. Catecholamines: mediator of the hypermetabolic response to thermal injury. Ann. Surg. 4:653-669.

28. Cherrington, A. D., J. L. Chiasson, J. E. Liljenquist, A. S. Jennings, V. Keller, and W. W. Lacy. The role of insulin and glucagon in the regulation of basal glucose production in the postabsorptive dog. J. Clin. Invest. 58:1407-1418.

29. Ward, W. K., J. D. Best, J. B. Halter, and D. Porte, Jr. 1984. Prolonged infusion of somatostatin with glucagon replacement increased plasma glucose and glucose turnover in man. J. Clin. Endocrinol. Metab. 58:449-453, 1984.

30. Brown, P. M., C. V. Tompkins, S. Juul, and P. H. Sonken. Mechanism of action of insulin in diabetic patients: a dose-related effect on glucose production and utilization. Br. Med. J. 1:1239-1242, 1978.

31. Wolfe, R. R., J. R. Allsop, and J. F. Burke. 1979. Glucose metabolism in man: responses to intravenous glucose infusion. Metab. Clin. Exp. 28:210-219.

32. Clowes, G. H. A., H. T. Randall, and C. J. Cha. 1980. Amino acid and energy metabolism in septic and traumatized patients. $J$. Parenteral and Enteral Nutrition. 4:195-205.

33. Marliss, E. B., T. T. Aoki, T. Pozefsky, A. S. Most, and G. F. Cahill. 1971. Muscle and splanchnic glutamine and glutamate metabolism in postabsorptive and starved man. J. Clin. Invest. 50:814-817.

34. Wolfe, R. R., F. Jahoor, D. N. Herndon, and E. J. Peters. 1986. Amino acid and urea kinetics in severely burned children assessed by means of stable isotopic tracers. 7th International Congress on Burn Injuries, Melbourne, Australia. 